\title{
Wisdom and organizational citizenship behavior: An empirical research
}

\author{
Simran Singla and Vanshika Beri \\ Department of Psychology, University of Delhi, Delhi
}

\begin{abstract}
An exploratory research was done to compare people with different levels of wisdom (\& its components) on OCB. An online survey gathered data from two twenty-five private-sector HR employees from Delhi-NCR. The analysis was done using SPSS 20. It was found out that there is a significant difference in people with high and low levels of experience, emotional regulation, humor, reflectivity, and openness with respect to the OCB. Overall wisdom does seem to interact with OCB, but no such interaction was found with respect to gender and OCB. There was no significant interaction between gender and wisdom with respect to OCB. Finally, all the dimensions of wisdom and the overall level of wisdom had significant positive relation with OCB in both females and males.
\end{abstract}

Keywords: wisdom, organizational citizenship behavior, H.E.R.O.E. model, experience, emotional regulation

In-role task performance by the employees is what an organization needs at the start to survive, but with time, it will need its employees engaging in tasks beyond their job descriptions to become successful; which is probably why OCB can be a great predictor of an organization's functioning (Organ, 1988). For this, organizations need employees who can readily engage in behavior that benefits others (emotional regulation, reflectivity, humor) and the organization (openness, experience) which are the components of wisdom (Webster, 2007; Ardelt, 2010). Considering that India's startup ecosystem is growing at a fast pace, the organizations would definitely need the know-how of how to increase their efficiency and productivity. Vaill (2007) suggested that wisdom governs the association of people in an organization, which might have some indirect effect on OCB. Even though researchers have focussed on wisdom and OCB separately, not many pieces of research are conducted considering them together, and almost none in the Indian context. Therefore, the present research is focussing on components of wisdom, gender and $\mathrm{OCB}$, having the potential to contribute to Indian organizations and organizations at large.

\section{Organizational citizenship behavior}

According to Schnake (1991), OCB is an altruistic behavior displayed by an employee at an individual, group and organizational level. This definition depicts the idea that OCB is a kind of behavior that is neither expected nor required, employees voluntarily engage in behavior that is not written formally in their job description (Muchinsky, 2006). Acts like helping out a teammate/mentoring an intern, or clocking more time for the projects are all part of OCB. Muchinsky (2006) mentioned five dimensions altruism (also called helping behavior), conscientiousness (desire to do tasks well),

\section{Author Note}

\section{Simran Singla}

Department of Psychology, University of Delhi, Delhi

Vanshika Beri

Department of Psychology, University of Delhi, Delhi

We have no known conflict of interest to disclose

Correspondence concerning this article should be addressed to

Simran Singla

Department of Psychology, University of Delhi, Delhi

E-mail: singla99simran@gmail.com courtesy (showing respect towards others'), sportsmanship (sense of fellowship) and civic virtue (moral \& righteous behavior). Researchers have found out that people who are high on agreeableness and conscientiousness are more likely to depict OCB. Further, if people perceive that they are treated fairly in an organization, they are likely to develop a positive attitude towards the organization and thereby are likely to depict OCB (Muchinsky, 2006).

People high on OCB feel that their job is useful and experience work meaningfulness at the end of the day, i.e., they feel more energized and are productive (Lam, Van, \& Roussin, 2016). Employees high on OCB are likely to perform better on their jobs in terms of their work volume, quality, relationship with others, are maintains cohesiveness and unity of the organization (AlMahasneh, 2015); by increasing the productivity of managers and employees (Podaskoff et al., 2000; cited in Al-Mahasneh, 2015); and are less likely to leave their jobs (Sunday, 2016).

\section{Wisdom}

When someone tells you to imagine how a wise person would look, there comes an image of a peaceful looking, old person, most probably an old saint or a grandparent. Why? Maybe because we consider a wise person as someone who has the experience and practical knowledge of life. The same was defined by Webster (2007) as the application of life experiences to facilitate the development of self and others. In other words, wise people, unlike others, apply their experience to not only develop themselves but also others. Broadly, implicit and explicit theories are used to understand wisdom. Implicit theories are the mental representations of life experiences, meanwhile, explicit theories involve the application of these life experiences for problem-solving and decision-making. Deriving from the implicit theory, Webster (2007) gave the H.E.R.O.E. model, which consists of five components (Humor, Experience, Reflectivity, Openness, \& Emotional Regulation), that are susceptible to change overtime. The present research is based on this model.

\section{Review of literature}

A paucity of researches where wisdom and OCB were taken together, is one of the main reasons why this study was initiated. Further, not many studies could be found on any of the components independently, therefore, related terms were used to understand the components. 


\section{Humor}

In general, humor is associated with sharing laughter. Webster (2010) also saw humor as bonding with others by easing up the situation and as a method to combat life challenges by accepting and perceiving them as ironies and jokes, which is probably why he added it as one of the components of wisdom. Accordingly, bonds among the employees are likely to form easily in the presence of humor. Further, humor, in an organizational context, is one of the strongest ways to enhance OCB (Allameh, Masoumzadeh, Salehzadeh, 2014). Other studies have shown that humor can also be considered as one of the predictors of OCB (Javadi, Poor, \& Salehzadeh, 2013). This leads to our first hypothesis.

H1: There would be a significant difference in participants with high and low levels of humor on organizational citizenship behavior.

\section{Experience}

Experience generally involves the knowledge that people acquire through various life events. This can be helpful when solving problems, making decisions and living a more fulfilling life, a trait that is found in wise people (Webster, 2007). With age, experiences get enhanced, significantly affecting OCB (Seok, Mutang, Nawi, \& Wider, 2018; Salami, 2008; Cohen, 1993) experience in a particular field/job greatly increases their know-how of various skills and how tasks can be managed better (McCloy, Campbell, \& Cudeck, 1994) thus, giving them opportunities of displaying prosocial behavior, such as helping amateur employees, which is an important component of OCB. Another reason can be that when an employee works long-term with an organization, they tend to feel a sense of belonging to the organization, and display a need to give something back to it (Seok et al., 2018; Salami, 2008). This leads to our second hypothesis.

H2: There would be a significant difference in participants with high and low levels of experience on organizational citizenship behavior.

\section{Reflectivity}

Reflection starts with self-awareness (Eurich, 2017) wherein the person first understands their thought processes, and slowly introspects and questions their actions/behavior by dwelling deeper into their past and present keeping their own beliefs aside, a complex process which helps develop wisdom (Gluck, Bluck, \& Weststrate, 2018). This helps the individual make better decisions both for themselves and others. In an organizational context, employees are thereby able to adjust well (Ziaee, Aghaei, Abdi, \& Bagheri, 2013) by making strong emotional connections (Janis, 2013; cited in Ziaee et al., 2013); coping with stressors (Jain \& Sinha, 2005; cited in Ziaee et al., 2013); and being optimistic (Besharat, 2003; cited in Ziaee et al., 2013). This leads to our third hypothesis.

H3: There would be a significant difference in participants with high and low levels of reflectivity on organizational citizenship behavior.

\section{Openness}

Openness involves going out of one's comfort zone (Fiske, 1994) to try and examine something new by being flexible enough to let external and internal factors influence them (McCrae, 1992). Such people like to think differently and are open to new ideas and perspectives, letting them experience diversity and helping them to become wiser (Webster, 2007) thereby increasing the chances of exhibiting OCB (Patki \& Abhyankar, 2016; Ahmadizadeh, Heydarinejad, \& Taheri, 2013; Elanain, 2007) by using their knowledge creatively to enhance the effectiveness of the organization, by going beyond their in-role tasks. This leads to our fourth hypothesis.

H4: There would be a significant difference in participants with high and low levels of openness on organizational citizenship behavior.

\section{Emotional regulation}

Emotional regulation involves the person being sensitive towards emotions and the acts of self and others under unique circumstances, through which understanding and regulating others' behaviors becomes easier. This skill is an important one seen in wise people, which is probably why Webster (2007) used it as a component of wisdom. People who are high on emotional regulation are likely to exhibit OCB (Pradhan, Jena, \& Bhattacharya, 2016). Employees who learn to control their emotions show marked improvement in their work behavior and exert positive behavior in the organization (Ng, Ke, \& Raymond, 2014) for example, by praising other employees. This leads to our fifth hypothesis.

H5: There would be a significant difference in participants with high and low levels of emotional regulation on organizational citizenship behavior.

\section{Gender, organizational citizenship behavior and wisdom}

Finally coming to our last variable, i.e., gender, there are mixed findings on how gender is related to wisdom as well as OCB. Even though a study found some role of gender in wisdom (Maroof, Zebkhan, Anwar, \& Anwar, 2015) on some of its dimensions, many other studies suggest that they are unrelated variables (Gluck, Strasser, \& Bluck, 2009; Ardelt, 2009; Le, 2008). Some studies show conscientiousness, responsibility and helpful behavior as the aspects of OCB which are high for females while sportsmanship for males (Rauf, 2018); along with other studies suggesting a significant relationship between the two variables (Anu \& Radhey, 2017; Ehrhart \& Godfrey, 2003). However, there are studies depicting no gender differences in OCB (Cheung \& Cheung, 2013; Beauregard, 2012; Lambert, Hogan, Dial, Altheimer, \& Barton-Bellessa, 2012; Lev \& Koslowsky, 2012; Podsakoff, MacKenzie, Paine, \& Bachrach, 2000). This leads to our sixth hypothesis.

H6: There would be significant interaction of gender and wisdom on organizational citizenship behavior.

H7: There would be a significant correlation between components of wisdom (including overall levels of wisdom) and organizational citizenship behavior across gender.

\section{Objectives of the study}

- To compare people with high and low levels of experience on OCB.

- To compare people with high and low levels of emotional regulation on OCB.

- To compare people with high and low levels of humor on OCB.

- To compare people with high and low levels of reflectivity on OCB.

- To compare people with high and low levels of openness on OCB.

- To study the interactional effect of gender and wisdom on OCB.

- To study the correlation between components of wisdom (including overall wisdom) and OCB across gender. 
Table 1

Demographic details of the participants

\begin{tabular}{lcc}
\hline Characteristics & $\mathrm{n}$ & $\%$ \\
\hline Gender & 113 & \\
Female & 112 & 50.2 \\
Male & & 49.8 \\
Age (in years) & 63 & \\
$21-30$ & 118 & 28.0 \\
$31-40$ & 35 & 52.4 \\
$41-50$ & 9 & 15.6 \\
$50<$ & & 4.0 \\
Education Qualification & 24 & 10.7 \\
Under Graduate & 195 & 86.7 \\
Post Graduate & 6 & 2.7 \\
Ph.D./M.Phil. & & \\
\hline
\end{tabular}

$\mathrm{n}=$ Sample size $\%$ $\%$ Percentage

\section{Instruments}

Self-Assessment Wisdom Scale by Webster $(2003,2007)$. The SAWS (Webster, 2003, 2007) measures five components of wisdom: openness, emotional regulation, humor, critical life experience, and reminiscence and reflectiveness. It consists of 40 items presented with a 6-point Likert scale from "strongly disagree" to "strongly agree."Webster $(2003,2007)$ reported a Cronbach's alpha of 0.90 .

Organizational Citizenship Behavior Checklist by Spector and Fox (2011). The OCB-C, 20 item Checklist, uses a 5-point frequency scale ranging from $1=$ Never to $5=$ Every day. The checklist is divided into two subscales: acts directed toward the organization that benefits the organization (OCBO) and acts directed toward coworkers that help with work-related issues (OCBP). Fox and Spector (2011) reported Cronbach's alpha of .97 for the total scale, .92 for OCBO and .91 for OCBP. However, the present research took overall OCB score into consideration.

\section{Procedure}

The survey research design was used in the current study, wherein the participants were asked to fill an online questionnaire. Participants were selected through purposive sampling on the basis of an inclusion criterion (HR employee of a private-sector organization across Delhi-NCR). The gathered data were analyzed using SPSS (version 20).

\section{Research design}

Initially, the normality check was done by testing the skewness and kurtosis. It was found out that the data was slightly skewed and slightly high on kurtosis. Since the sample size is large (i.e., greater than 30), the central limit theorem (Field, 2009) was applied. According tohim, if the sample size is large enough (more than 30 ), the central limit theorem can be used to treat sampling distribution as normal.

For the analysis of the first five hypotheses, an independent sample t-test was used. Since no study was available which explored both components of wisdom and gender together, independent sample t-test seemed a better option as compared to any other higher-order statistical technique. Since a few studies were found which explored overall wisdom and gender together, two-way ANOVA was used for the sixth hypothesis. Further, a correlational method was used for the seventh hypothesis. After the analysis, the result tables were formed and then interpreted. Figure 1 depicts the design of the current study.

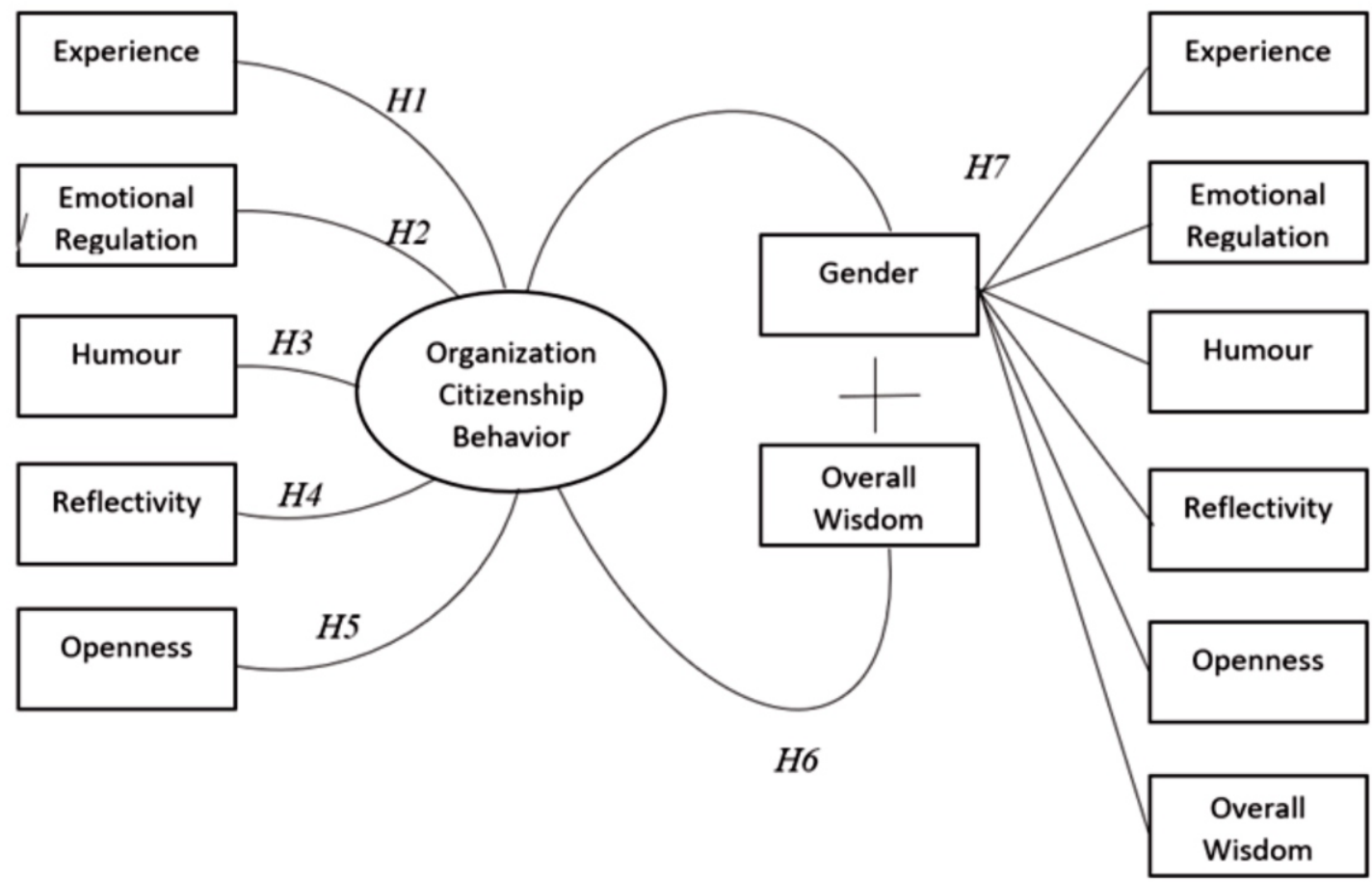

Figure 1: Design of the Study 


\section{Results}

results, so obtained, are reported in the following tables.

The analysis of the data was done in SPSS (version 20) and the

Table 2

Mean and SD for the OCB scores for participants with high and low levels of components of wisdom

\begin{tabular}{lcllll}
\hline Variables & $\begin{array}{c}\text { Value of } \\
\text { Median Split }\end{array}$ & Level & $\mathrm{n}$ & $\mathrm{M}$ & $\mathrm{SD}$ \\
\hline Experience & 35 & High & 117 & 72.91 & 12.10 \\
& \multirow{2}{*}{34} & Low & 108 & 57.86 & 14.44 \\
Emotional & \multirow{2}{*}{34} & High & 115 & 72.37 & 12.44 \\
Regulation & \multirow{3}{*}{34} & Low & 110 & 58.70 & 14.79 \\
Humour & & High & 114 & 73.24 & 11.89 \\
& \multirow{3}{*}{33} & High & 111 & 57.93 & 14.41 \\
Reflectivity & & Low & 110 & 72.74 & 12.19 \\
& & High & 119 & 73.24 & 14.63 \\
Openness & & Low & 106 & 57.21 & 14.04 \\
\hline
\end{tabular}

$\mathrm{n}=$ sample size; $\mathrm{M}=$ Mean; $\mathrm{SD}=$ Standard Deviation

Table 2 consists of the descriptive statistics for each of the variables. The results show that people who have scored high on experience, emotional regulation, sense of humor, reflectivity and openness have high scores on OCB as compared to people who scored low on these components.

\section{Table 3}

t test for differences between $O C B$ of participants with high and low levels of components of wisdom

\begin{tabular}{lllll}
\hline & Levels & $\mathrm{df}$ & $\mathrm{t}$ & $\mathrm{p}$ \\
\hline Experience & High & 209.51 & 8.44 & $.000^{* *}$ \\
Emotional Regulation & Low & & & \\
& High & 213.11 & 7.48 & $.000^{* *}$ \\
Humour & Low & & & \\
& High & 213.08 & 8.68 & $.000^{* *}$ \\
Reflectivity & Low & & & \\
Openness & High & 212.32 & 8.02 & $.000^{* *}$ \\
& Low & & & \\
& High & 223.00 & 9.24 & $.000^{* *}$ \\
& Low & & & \\
\hline
\end{tabular}

Two- tailed, ** Significant at .01 level

An independent sample $t$ test was conducted on the first five hypotheses, the results of which are shown in Table 3 . The results Table 4

$F$ values for interaction between gender, levels of Wisdom and $O C B$

\begin{tabular}{llll}
\hline & df & F & p \\
\hline Wisdom & 1 & 66.16 & $.00^{* *}$ \\
Gender & 1 & 00.37 & .54 \\
Wisdom*Gender & 1 & 00.01 & .92 \\
Error & 221 & & \\
\hline
\end{tabular}

**Significant at.01 level show that there is a significant difference between participants with high and low levels of experience, emotional regulation, sense of humor, reflectivity and openness on OCB.

Two-way ANOVA was done for hypothesis 6, the results of which are shown in Table 4. The results show that there is a significant difference in the level of wisdom on OCB. Further, the results showed that there was no significant difference of gender on OCB. For interaction effect, the results show that there is no significant interaction between level of wisdom and gender on OCB.

Table 5

Correlation values for relationships between dimensions of wisdom and overall OCB across gender

\begin{tabular}{llc}
\hline & Gender & Pearson Correlation \\
\hline Experience & Female & $.51^{* *}$ \\
& Male & $.56^{* *}$ \\
Emotional Regulation & Female & $.48^{* *}$ \\
& Male & $.52^{* *}$ \\
Humour & Female & $.52^{* *}$ \\
& Male & $.53^{* *}$ \\
Reflectivity & Female & $.50^{* *}$ \\
& Male & $.52^{* *}$ \\
Openness & Female & $.54^{* *}$ \\
& Male & $.54^{* *}$ \\
Total of Wisdom & Female & $.53^{* *}$ \\
& Male & $.55^{* *}$ \\
\hline
\end{tabular}

**Correlation is significant at the .01 level (2-tailed)

Finally, correlational analysis was done for the last hypothesis, results of which are reported in Table 5. It can be said that there is a significant positive relation between all the dimensions of wisdom, including the total of wisdom and OCB in both females and males. 


\section{Discussion}

The purpose of the study was to explore whether the level of wisdom and its components make any difference in OCB. We expected that employees who are high on wisdom and its components are likely to exhibit OCB.

Our findings suggest a strong and positive relation between humor and OCB with a significant difference between employees high and low on the variable, which is also confirmed in some past researches (Allameh et al., 2014; Javadi et al., 2013). Having a sense of humor can make a person accept the ironies of life as they come, making them more accepting of them. Therefore, instead of taking the challenges and probable failures to heart, they might be willing to look past it as a learning experience, thus, increasing the chances of them being more satisfied with their performance. Humor also tends to make people feel satisfied with the situation, hence, letting them stay calm even in stressful situations. Doing so can make them better at handling challenges, making better decisions and solving problems. Such individuals also become role models for other employees, specifically the newer ones and motivating them to do the same. Having a sense of humor also is a way to ease the tension in the environment and make the situation more comfortable between people by building a good rapport quickly and efficiently, especially with employees who are nervous in the new surroundings. This might also lead to a better bond between them, thus, leading to a sense of belongingness with each other, and slowly with the organization as well.

Next, a strong and positive relationship between experience and $\mathrm{OCB}$, with a significant difference between employees high and low on the variable was found, which is also confirmed in some past research (Seok et al., 2018; Wagner \& Ruch, 2000). As people work in a particular field, the knowledge they gain makes them skilled at it. Employees use this knowledge for problem-solving and critical decision-making. Some organizations have policies that people will get promotions on the basis of either seniority or long tenure, the reason being that experience has the ability to enhance the efficiency of the employees, and in turn of the organization. This also gives them the expertise of handling and guiding their juniors to solve problems or helping them in completing tasks; they can give suggestions as to how the work environment can be improved. This attitude of the organization can also help in the enhancement of selfesteem of employees by letting them know that they matter to the organization. All this might lead to job satisfaction, thereby, increasing OCB.

Further, a strong and positive relation between reflectivity and $\mathrm{OCB}$, with a significant difference between employees high and low on the variable was found, which is also confirmed in some past researches (Patki \& Abhyankar, 2016; Ahmadizadeh et al, 2013; Elanain, 2007). Employees high on openness tend to be flexible and willing to bring changes in life by grabbing opportunities to groom their personalities, i.e., learning something new, enrolling for different courses and might volunteer to work on new tasks; which contributes to their ability to creatively solve challenges and being more adaptable to whatever the situation demands of them.

Being flexible tends to make the person more willing to accept themselves for who they are and try to change themselves for the better, which can be done through self-reflection. Our findings suggest a strong and positive relation between reflectivity and OCB, with a significant difference between employees high and low on the variable, which is also confirmed in some past researches (Ziaee et al., 2013; Moghadam \& Bahr-o-Olom, 2010). Self-awareness is the path to self-reflection. By introspecting and exploring one's thoughts, emotions and motives, they can gain access as to how they carry themselves in their work environment. Once they become aware of where they stand at present, it would become easier to understand what changes must be brought to enhance their performance. This is what leads to emotional regulation. Our findings also suggest a strong and positive relationship between emotional regulation and $\mathrm{OCB}$, with a significant difference between employees high and low on the variable, which is also confirmed in some past research (Pradhan, et al., 2016; $\mathrm{Ng}, 2014)$. When an employee becomes aware of their present position and what changes they must make for a better future, it can become easier for them to manage and change their emotional needs to suit their future goals. By doing so, they may also become capable of understanding the emotional states of others as well, thus, helping them through the change for the better by maybe encouraging them in difficult times or listening to their worries. Such employees who are aware and in control of their emotions, can also become good mentors for other employees and new interns, increasing the bond among them, thus, indirectly having an effect on OCB.

Finally, a positive and significant relation between wisdom (it's components) and $\mathrm{OCB}$, irrespective of gender was found. Gender, alone does not seem to make any difference to OCB. Meanwhile, overall wisdom does seem to have some difference on OCB. However, wisdom and gender when taken together, don't seem to interact with OCB. Some researches also revealed that there is no relationship between gender and OCB (Cheung \& Cheung, 2013; Beauregard, 2012; Lambert et al., 2012; Lev \& Koslowsky, 2012; Podsakoffet al., 2000).

Katz and Kahn (1978) noticed that when the members of any organization are confined to perform only what is required by the organization, the organization will collapse. Considering OCB is the backbone of any organization, it is important to hire employees who are high on it. The findings of this research can be utilized by the organizations to evaluate and understand the levels of wisdom of an employee. It is important for the organizations to understand the importance of people who are high on wisdom since people high on wisdom seem to have very rich life experiences which can enhance their knowledge about a particular field; are high on self-awareness, because of which they are better able to regulate their emotions and that of others'. Moreover, they can contribute to the organization through their creative ideas because they can easily adapt to changes. These findings can be used by an organization in both their hiring processes as well as to evaluate their employees.

The organizations can make efforts to enhance the levels of wisdom in their employees by creating environments that help enhance all the five components of wisdom. This can be done through experiential workshops which can give the employees supplementary knowledge about their fields of expertise. Further, the employees can be motivated to attend these workshops by giving them rewards (like certifications \& gift vouchers). Employers can also encourage their employees to implement what they have learned and a routine check can be done to check the effectiveness of the workshops. Besides workshops, employees can be introduced to the system of job rotation, which can give diverse perspectives as to how work is carried out in an organization. 
Similarly, seminars on soft skills, like emotional intelligence, can be done to increase the level of self-awareness among the employees, through which they might be better able to reflect on their emotions and thoughts, and use this knowledge to regulate their emotions and that of others' as well. Encouraging activities like Johari Window, a technique that helps people better understand their relationship with themselves and others; and journaling which is known to have a cathartic effect on the individual, can be useful for releasing their stresses and making them more aware of their emotions. In addition to this, a safe space (like organizational counselors) can be made available to the employees to help them relieve their negative emotions. Through such initiatives, the workers might experience a positive bond and sense of belongingness with the organization thus, affecting OCB.

\section{Limitations and future suggestions}

The research study was an exploratory study with basic research design and, therefore, did not focus on causal relation. Future researchers can do an in-depth analysis by finding cause and effect relationships. Lastly, gender was not taken in much detail with the variable other than with the overall wisdom to see an interaction effect if there was any, which can be considered in depth along with other departments of the organization and public sector organizations to do a comparative study in the future.

Lastly, the research did not study the effect of gender along with the dimensions of wisdom, gender was used only with the overall level of wisdom. Future researchers can also study other departments in the organizations and a comparative study can be done. Further, the public sector was not taken into consideration. Future researchers can do comparative research between the public and private sectors.

\section{Conclusion}

The aim of the research was to explore whether the components of wisdom are making any difference in the OCB of people from the HR department of the private sector organizations in Delhi-NCR, India. The findings of the research suggest that people high on experience, emotional regulation, humor, reflectivity and openness tend to also be high on OCB. Further, gender alone does not seem to make any difference to OCB. Meanwhile, overall wisdom does seem to have some difference in OCB. However, wisdom and gender when taken together, don't seem to interact with it. Finally, all the dimensions of wisdom and the overall level of wisdom had a significant positive relation with $\mathrm{OCB}$ in both females and males.

\section{Acknowledgments}

This research paper is made possible through the help and support from everyone, especially participants for lending their valuable time. We would also like to thank Dr. Nasrina Siddiqi for her constant guidance; Dr. Jeffery Dean Webster for sharing some of his work; and Dr. Paul E. Spector and Suzy Fox for permitting the use of their questionnaire. Lastly, we are also grateful to our families and friends, Snehaa Sweekruti Dash, Simran Gill, and Anaadya Gupta, for helping in gathering data.

\section{References}

Ahmadizadeh, Z., Heydarinejad, S., \& Taheri, A. (2013). Investigation of the relationship of openness to experience and organizational citizenship behaviour. International Research Journal of Applied and Basic Sciences, 4(8), 2225-2229.

Allameh, S.M., Masoumzadeh, A., \& Salehzadeh, R. (2014). Studying the relationship between humor, job satisfaction and organizational citizenship behavior. Journal of Applied Science and Agriculture, 9(4), 1697-1703.

Al-Mahasneh, M. A. (2015). The impact of organizational citizenship behavior on job performance at greater amman municipality. European Journal of Business and Management, 7(36), 108-118. ISSN 2222-2839.

Anu, P. P., \& Radhey, S. (2017). Gender difference in of organizational behavior (OCB) and motives underlying OCB. Psychological Behavioral Science International Journal, 4(2), 1-5.

Ardelt, M. (2009). How similar are wise men and women? A comparison across two age cohorts. Research in Human Development, 6(1), 9-26.

Ardelt, M. (2010). Age, experience, and the beginning of wisdom. In D. Dannefer and C. Phillipson (Eds.), The SAGE handbook of social gerontology (pp. 306-316). Sage Publication.

Beauregard, T. A. (2012). Perfectionism, self-efficacy and OCB: The moderating role of gender. Personnel Review, 41(5), 590-608.

Cohen, A. (1993). Age and tenure in relation to organizational commitment: MetaAnalysis. Basic and Applied Social Psychological, 14(2), 143-159.

Cheung, F.Y.L., \& Cheung, R.Y.H. (2013). Effect of emotional dissonance on organizational citizenship behavior: Testing the stressor-strain-outcome model. The Journal of Psychology, 147(1), 89-103.

Elanain, H. (2007). Relationship between personality and organizational citizenship behavior: does personality influence employee citizenship? International Review of Business Research Papers, 3(4), 31-43.

Ehrhart, M. G., \& Godfrey, E. (2003). Schemas for organizational citizenship behavior in gender-stereotyped jobs. Poster presented at the 18th Annual Conference for the Society of Industrial and Organizational Psychology, Orlando, FL.

Eurich, T. (2017). Insight. New York: Crown Business.

Field, A. (2009). Discovering statistics using SPSS. London: Sage publication.

Fiske, D.W. (1994). Two cheers for big five. Psychological Inquiry, 5(2), 123-124.

Glück, J., Strasser, I., \& Bluck, S. (2009). Gender differences in implicit theories of wisdom. Research in Human Development, 6(1), 27-44.

Glück, J., Bluck, S., \& Weststrate, N. (2018). More on the MORE life experience model: What we have learned (so far). The Journal of Value Inquiry, 53, 349-370. DOI: 10.1007/s10790-018-9661-x.

IBM Corp. released (2011). IBM SPSS statistics for windows, version 20.0. IBM Corp. Javadi, M.H.M., Poor, S.H., \& Salehzadeh, R. (2013). Studying the relationship between humor and organizational citizenship behavior. International Journal of Academic Research in Accounting, Finance and Management Sciences, 3(3), 146151

Katz, D., \& Kahn, R.L. (1978). The social psychology of organizational (2 $2^{\text {nd }}$ ed.). Wiley.

Lam, C. F., Wan, W. H., \& Roussin, C. J. (2016). Going the extra mile and feeling energized: An enrichment perspective of organizational citizenship behaviors. Journal of Applied Psychology, 101(3), 379-391.

Lambert, E. G., Hogan, N. L., Dial, K. C., Altheimer, I., \& Barton-Bellessa, S. M. (2012). Examining the effects of stressors on organizational citizenship behaviors among private correctional staff: A preliminary study. Security Journal, 25(2), 152172.

Le, T. N. (2008). Age differences in spirituality, mystical experiences and wisdom. Ageing and Society, 28, 383-411.

Lev, S., \& Koslowsky, M. (2012). Teacher gender as a moderator of the on-the-job embeddedness OCB relationship. Journal of Applied Social Psychology, 42(1), 81-99.

Maroof, R., Zeb Khan, M.J., Anwar, M., \& Anwar, A. (2015). A cross-sectional study of wisdom: A matter of age and gender. FWU Journal of Social Sciences, 9(2), 63-71.

McCloy, R.A., Campbell, J.P., \& Cudeck, R. (1994). A confirmatory test of a model of performance determinants. Journal of Applied Psychology, 79(4), 493-500.

McCrae, R. R. (1992). Openness to experience as a basic dimension of personality. Paper presented at the annual convention of American Psychological Association. Washington D.C.

Moghadam, S.S., \& Bahr-o-Olom, H. (2010). The relationship between emotional intelligence and mental skills of female students of Shahroods Industrial University. The Seasonal Journal of Sports Psychology, 1, 1-10.

Muchinsky, P. M. (2006). Psychology applied to work: An introduction to industrial and organizational psychology. Thomson Wadsworth.

Ng, S. M., Ke, G. N., \& Raymond, W. (2014). The mediating role of work locus of control on the relationship among emotional intelligence, organizational citizenship behaviours, and mental health among nurses. Australian Journal of Psychology, 66(4), 207-215.

Organ, D. (1988). Organizational citizenship behavior: The good soldier syndrome. Lexington Books.

Patki, S. M., \& Abhyankar, S. C. (2016). Big five personality factors as predictors of organizational citizenship behaviour: A complex interplay. The International Journal of Indian Psychology, 3(2), 136-146. 
Podsakoff, P.M., MacKenzie, S.B., Paine, J.B., \& Bachrach, D.G. (2000) Organizational citizenship behaviors: A critical review of the theoretical and empirical literature and suggestions for future research. International Journal of Management, 26(3), 513-563.

Pradhan, R. K., Jena, L. K., \& Bhattacharya, P. (2016). Impact of psychological capital on organizational citizenship behavior: Moderating role of emotional intelligence. Cogent Business and Management, 3(1), 1194-174. DOI: 10.1080/23311975.2016. 1194174.

Rauf, F.H.A. (2018). Engagement of organizational citizenship behavior: Does gender make differences? Journal of Management, 14(1), 1-10.

Salami, S. O. (2008). Demographic and psychological factors predicting organizational commitment among industrial workers. Anthropologist, 10(1), 31-38.

Schnake, M. (1991). Organizational citizenship: A review, proposed model, and research agenda. Human Relations, 44, 735-759.

Seok, C.B., Mutang, J.A., Md. Nawi, N. H., \& Wider, W. (2018). The link between employees' organizational tenure and citizenship behaviour: Do different types of trust play important role? International Journal of Engineering and technology, 7(2), 1036- 1040. DOI: 10.14419/ijet.v7i2.29.1430.

Spector, P., \& Fox, S. (2011). Organizational citizenship behavior checklist (OCB-C) 20 Item. Retrieved fromhttp://shell.cas.usf.edu/ pspector/scales/ocbcpage.html

Sunday, F. S. (2016). Organizational citizenship behavior and turnover intent: A path analysis of Nigeria bankers' behavioural variables. American Journal of Applied Psychology, 5(6), 51-59. DOI: 10.11648/j.ajap.20160506.13

Vaill, P. B. (2007). Organizational epistemology Interpersonal relations in organizations and the emergence of wisdom. In E. H. Kessler and J. R. Bailey (Eds.), Handbook of organizational and managerial wisdom (pp. 327-355). Thousand Oaks, CA: Sage Publication.

Webster, J. D. (2003). An exploratory analysis of a self-assessed wisdom scale. Journal of Adult Development, 10, 13-22.

Webster, J. D. (2007). Measuring the character strength of wisdom. The International Journal of Aging and Human Development, 65, 163-183. DOI: 10.2190/AG.65.2.d.

Webster, J. D. (2010). Wisdom and positive psychosocial values in young adulthood. Journal of Adult Development, 17, 70-80.

Ziaee, A., Aghaei, N., Abdi, K., \& Bagheri, M. (2013). Relationship between emotional intelligence and organizational citizenship behavior among sport and youth head offices of western states of Iran. International Journal of Advanced Scientific and Technical Research, 3(6), 564-557.

Received July 24, 2020

Revision received July 29, 2020

Accepted August 1, 2020 